greater than 0.05). No significant differences in serum LTB4 level also were showed among the three genotypes in this locus within the same age class by further subgroup [seniors group ( $\geq 60$ years old) and early onset group ( $<60$ years old) analysis (all $p$ values were greater than 0.05).

Conclusions The serum LTB4 level is significantly higher in UAP patients and has significant correlation with the risk of UAP, but unrelated with ALOX5AP gene SG13S114 polymorphism.

\section{GW23-e1093 RELATIONSHIP OF THE SERUM LEUKOTRIENE B4 LEVEL WITH THE RISK OF UNSTABLE ANGINA PECTORIS AND THE ARACHIDONATE 5-LIPOXYGENASE ACTIVATING PROTEIN GENE SG13S114T/A POLYMORPHISM}

doi:10.1136/heartjnl-2012-302920k.17

He Guo-Ping, Ye Shan, Hui Jing-Jiao, Shen Dan-Dan, Qi Chuan-Ping, Xu Lian-Hong. Affiliated Wujin Hospital of Jiangsu University, Changzhou 213002, China

Objectives To investigate the association of the serum leukotrienes (LT) B4 level with the risk of unstable angina pectoris (UAP) and the arachidonate 5-lipoxygenase activating protein (ALOX5AP) gene SG13S114T/A polymorphism in Chinese Han population of Sunan region.

Methods The polymorphism in the ALOX5AP gene SG13S114T/A was genotyped by PCR and restriction fragment length polymorphism analysis, and the serum LTB4 level (M/IOR) was measured by ELISA in 141 UAP patients (UAP group) and 132 subjects without coronary heart disease (control group).

Results The serum LTB4 level in UAP group was significantly higher than the one in control group $(352.52 / 255.48 \mathrm{pg} / \mathrm{ml}$ vs $200.28 / 237.10 \mathrm{pg} / \mathrm{ml}, \mathrm{p}<0.001$ ), and by multiple factor such as gender, age, hypertention, smoking, diabetes and hyperlipidaemia) logistic regression analysis, the serum LTB4 level was correlation with the risk of UAP. No significant differences in serum LTB4 level were found among AA, AT and TT genotypes of ALOX5AP gene SG13S114T/A in patients with UAP $(347.36 / 201.92 \mathrm{pg} / \mathrm{ml}$ vs $361.89 / 262.23 \mathrm{pg} / \mathrm{ml}$ vs $365.18 / 268.43 \mathrm{pg} / \mathrm{ml}$, all $\mathrm{p}$ values were 